\title{
An East African safari
}

\author{
Achieving a balance
}
John L. Cox, Professor, Department of Psychiatry, School of Postgraduate Medicine, University of Keele, Stoke-on-Trent

To have been external examiner for the Masters Degree in Psychiatry (M Med) of the University of Nairobi for the last three years was an unusually stimulating opportunity, not only for a 'busman's holiday' (as my registrar called it) and a 'good enough' reason for a return to Africa, but it also enabled me to contribute again to training East African psychiatrists - a task which I first undertook in 1972 when a lecturer at Makerere University in Uganda. Because of the civil wars in Uganda, however, the Department of Psychiatry in neighbouring Kenya has now flourished and become one of the most substantial Departments in Central and Southern Africa. The Department, which includes one 'full' professor, two associate professors, four lecturers, two tutorial fellows, will soon have its own teaching in Kenyatta National Hospital as well as accommodation at the Mathari Mental Hospital, made famous by the pioneer observations of Carothers. In addition to its commitment to postgraduate training the Department provides three months teaching for other doctors taking an M Med in Medicine and Paediatrics and also teaches 150 medical students each year.

This year we examined five candidates for the $\mathbf{M}$ Med in Psychiatry (approximately equivalent in standard to the MRCPsych examination) and there were a further five who did not sit the examination because they had not completed their theses in time. There were two candidates taking Part I of the M Med but only one was successful. Three of the five doctors who were taking Part II passed the examination.

Last year, I revisited Uganda for the first time since 1974 and experienced again the generosity and fortitude of the people, as well as the great beauty of the country. I could observe the persistence of the Department of Psychiatry at Mulago Hospital, which was holding its undergraduate examinations, and listened in to discussions about reviving the Makerere Masters Degree in Psychiatry - which was the first psychiatry postgraduate degree in Central Africa, but which had been dormant now for at least a decade. It was obvious to me that the civil wars had left behind very deep wounds indeed which still affected many aspects of national life including that of the
University; there was massive inflation and poor public services but the security in Kampala was vastly improved. Makerere retains its informal atmosphere characteristic of a residential campus university (with some similarities to Keele) and yet was still very vulnerable to the whims of Government policy, but nevertheless endeavoured to hold on to its academic freedom and indeed to restore its international prestige.

Uganda had always been a very different country to Kenya-more African and yet potentially as prosperous - but now the contrast was stark. Kenya appears to flourish and its ability to train psychiatrists is a clear example of this 'prosperity'. It is for the Kenyans themselves to describe their success and plans for the future, but it was evident to me that at the present time they seem determined to maintain a high standard of postgraduate training. How many trainees in Britain, for example, would attempt to submit a bound thesis as well as prepare for an examination at Membership level within three years - child psychiatry and mental handicap included?

This safari 'Back to Africa' was, therefore, as evocative and almost as memorable as my first journey 'Out of Africa' 15 years ago. It is, nevertheless, possible that other psychiatrists, from perhaps a more objective standpoint, would also be impressed by meeting these East African members of the Royal College of Psychiatrists who wish to retain close links with the UK and yet who work at the cutting edge of psychiatry in a rapidly developing country.

It is an irony that the attempt to achieve a manpower balance in the UK has inadvertently reawakened an interest in these specific training needs of registrars in Britain from overseas. My experience in East Africa suggested that the 'Overseas Desk' of the College may miss an important opportunity if their task is restricted only to providing international experience for visiting registrars to Britain and does not also give information to regional registrars who wish to work overseas.

Achieving a Balance has raised an important debate about the quality and relevance of psychiatric training in the UK for overseas doctors and of the 
ethics of the 'balance' between north and south. The growth of courses in 'developing country psychiatry' at the Institute of Psychiatry in London, Manchester and at Keele is, in my view, an entirely appropriate, if belated, response to the particular training needs of doctors, whether UK or foreign doctors, who plan to work in a developing country. One could speculate about the many reasons for the popularity of such courses at the present time. However, the problems of their assessment and my recent sojourn in East
Africa was a timely reminder that the balance of advantage between north and south is now more evenly weighted than any simplistic understanding of British colonial history, or of the more affluent north, would suggest.

It is, indeed, hoped that there could be a joint meeting between the Royal College of Psychiatrists and the Kenyan Psychiatric Association, which I have little doubt would be instructive to participants from whichever continent they come.

\title{
Community-oriented psychiatric care
}

\author{
Some ideas on training*
}

JosEPH ConNolly, Consultant Psychiatrist and IsAac Marks, Professor of Experimental
Psychopathology, The Maudsley Hospital and Institute of Psychiatry, London SE5

The College is debating how to train psychiatrists for community care (CC) that is spreading - ahead of hard evidence of its value for certain problems in the UK. Much future psychiatry will be practised in the community outside hospital within multidisciplinary teams not always led by a psychiatrist, and wherein the lead-rôle changes frequently within a single meeting depending on whose expertise and readiness to accept responsibility emerge.

The following is a list of preliminary ideas on how to equip trainees to work as community psychiatrists, making cogent and valued contributions to team-working. Academic and practical training is needed in most forms of mental health care delivery in diverse settings. Many of the tentative ideas for training to work with adults in CC also apply to the very young and the elderly, to other forms of care and to other care providers. Hands-on experience is required, as key worker for part of the team's caseload, in (6) to (13) following.

* Based on invited talk to and feedback from Open Forum of Royal College of Psychiatrists Education and Collegiate Trainees' Committees, March 1988.
Knowledge is needed of:

(1) the aim of CC to manage mental health problems in the least restrictive settings possible without losing the security, time continuity and depth obtainable in hospital care;

(2) the epidemiology of psychiatric disorder, relating it to the social geography of the community served (rural-urban differences, the homeless and migrants, etc);

(3) the biopsychosocial aspects of causes, presentations, management and outcome of the problems most likely to be seen, distinguishing observation from inference;

(4) the performance - criteria in cost-effective care delivery for the population served;

(5) how to make the most of the team's human resources, knowing each type of carer's core role and shared roles;

(6) how to (a) define the patient's main problems and personal, family, social and physical health context; (b) help each problem using team resources sensibly, taking account of patients (i) coming into the system, (ii) already in it, and (iii) likely to present in future; (c) rapidly summarise the salient features of (a) and (b) for clinical management and communication with other carers; 